\title{
Comparative analysis of different CVC dressing types convenience and economic effectiveness in allogeneic hemopoietic stem cell transplant recipients
}

Olga Ivanova, Julia Simakina, Marina Ermolova, Julia Oparina, Ekaterina Goncharova, Ludmila Zubarovskaya, Boris Afanasyev

First Pavlov State Medical University of St. Petersburg, St.Petersburg, Russian Federation

Contact: Olga Ivanova:

E-mail: ivolga36936@yandex.ru

\section{Introduction}

The care for critically ill patients in our clinic requires in most cases the central venous access for therapeutic interventions and diagnostics. The use of central venous catheters (CVCs) has its drawbacks, one of which is development of catheter-associated infections (CAI) found in $20-55 \%$ of patients with sepsis. CAI development leads to significant raise of treatment costs. The prevalence of CAI depends on intraluminal and exit site infections prophylaxis by using appropriate CVC maintenance equipment and techniques.

\section{Materials and methods}

A total of 112 of allogeneic hemopoietic stem cell transplantation recipients with AML, ALL, CML and AA were divided into 3 clinical groups based on dressing type used. All patients had CV accesss via v. jugularis interna dextra. In the 1st group $(n=38)$ sterile self-adhesive non-woven pads (Cosmopor) were used. In the 2nd group $(n=37)$ transparent Tegaderm Film dressings were used. In the 3rd group $(n=37)$ transparent gel pads Tegaderm CHG were used. Nurses from CVC care team evaluated patients' complaints and performed catheter site monitoring for possible presence of local inflammatory changes, allergic reactions and CVC displacement. In addition, dressings changing convenience, catheter site cultures results and economic aspects were analyzed.

\section{Results}

The catheter exit site bacterial colonization was lower in patients with Tegaderm CHG dressings (3.4\%), than in patients with non-woven pads (5.7\%) or Tegaderm Film (5.3\%) dressings. In most cases the exit site inflammation was caused by Staph.Aureus, Staph. Epidermidis, Kl.Pneumoniae or Enterococcus spp. All 1st group (non-woven pads) patients reported frequent dressing deformation requiring its replacement and skin discomfort due to residual adhesive material. Patients from the 2 nd (film pads) group complained of skin contraction in movement (23\%) dressing deformation (22\%), itching (18\%), while $37 \%$ of patients had no complaints. In the 3rd group (transparent gel pads) $92 \%$ of patients were satisfied with dressing performance, while $2 \%$ reported itching and 6\% movement restriction. From nurses' points of view non-woven pads were inconvenient due to the difficulties of exit site monitoring, need of frequent changing of soiled, wet or deformed dressings. Transparent films were more convenient due to better visual control and less dense change schedule (once 2-3 days). Gel pads were most convenient as they required changing only one in 5-7 days and provided good catheter fixation. The daily cost was greater for daily changed non-woven pads (4.35 euro), than for film pads (2.67 euro) or gel pads (1.72 euro).

\section{Conclusions}

Transparent gel pads (Tegaderm CHG) is optimal in post-transplant patients due to less frequent change, which leads to less frequent skin traumas and exit sites infections, is more convenient for patients and nurses. In addition, although gel pads are relatively more expensive, their use provide economic advantages to lower daily cost (1.5-2.5 less than other dressing types) and less frequent CAIs.

\section{Keywords}

Central venous catheters, CVC dressings, infection prophylaxis, nurses monitoring, daily cost. 


\section{| Сравнительный анализ удобства применения и экономической эффективности при использовании различных видов повязок для фиксации центрального венозного катетера}

Ольга Иванова, Юлия Симакина, Марина Ермолова, Юлия Опарина, Екатерина Гончарова, Людмила С. Зубаровская, Борис В. Афанасьев

Первый Санкт-Петербургский государственный государственный медицинский университет им. И.П. Павлова

\section{Введение}

Уход за критически больными пациентами требует в большинстве случаев доступа через центральный венозный катетер (ЦВК) для терапевтических вмешательств и диагностики. Применение ЦВК имеет свои недостатки, одним из которых является развитие катетер-ассоциированных инфекций (КАИ), которые выявляются у 20-55\% больных с сепсисом. Развитие КАИ приводит к существенному повышению затрат на лечение. Частота КАИ зависит от качества их профилактики внутри просвета катетера и на его входе с применением соответствующих устройств для ухода за ЦВК.

\section{Материалы и методы.}

Всего обследованы 112 больных после аллогенных трансплантаций гемопоэтических стволовых клеток (алло-ТГСК), куда входили больные с ОМЛ, ОЛЛ, ХМЛ и апластической анемией. Пациентов разделили на 3 клинические группы, основанные на использованном типе повязок. Все пациенты имели доступ к центральной вене через v. jugularis interna dextra. В 1-й группе $(\mathrm{n}=38)$ использовали стерильные самоклеящиеся нетканые прокладки (Cosmopor), во второй группе $(\mathrm{n}=37)$ прозрачные повязки Tegaderm Film, а в третьей группе (n=37) - прозрачные гелевые подушечки Tegaderm CHG. Сестры по уходу за ЦВК оценивали жалобы пациентов и проводили наблюдение за местом введения катетера на предмет возможного присутствия местного воспаления, аллергических реакций и смещения ЦВК. Кроме того, оценивали удобство смены катетеров, результаты микробных культур с катетера и экономические аспекты.

\section{Результаты}

Бактериальная колонизация на выходе катетера отмечалась реже в случаях применения повязок Tegaderm CHG (3.4\%), по сравнению с пациентами, у которых использовали non-woven pads (5.7\%) или Tegaderm Film (5,3\%). В большинстве случаев воспаление в месте выхода катетера было связано co Staph.aureus, Str. epidermidis,
Kl. pneumoniae или Enterococcus spp. У всех больных 1-й группы (non-woven pads) отмечалась частая деформация повязок, требующая их замены и раздражение кожи остатками адгезивного материала. Пациенты 2-й группы (пленочные прокладки) жаловались на стягивание кожи при движениях (23\%), деформацию повязок (22\%), зуд (18\%), тогда как $37 \%$ больных не предъявляли жалоб. В 3-й группе (с прозрачными гелевыми прокладками) 92\% больных были удовлетворены состоянием повязок, $2 \%$ сообщали о зуде и $6 \%$ - об ограничении движений. По мнению медсестер, нетканые прокладки были неудобными из-за проблем с осмотром выходной области катетера, необходимостью частой замены загрязненных, сырых или деформированных повязок. Прозрачные пленки были более удобными в связи с лучшим визуальным контролем и менее частыми заменами (1 раз в 2-3 дня). Гелевые прокладки были наиболее удобными, так как требовали замены 1 раз в 5-7 дней и обеспечивали хорошую фиксацию катетера. Ежедневные расходы при этом были выше, чем для нетканых прокладок (4.35 евро), пленочных прокладок (2.67 евро), или гелевых подушечек (1.72 евро).

\section{Выводы}

Прозрачные гелевые прокладки (Tegaderm CHG) оптимальны у больных после трансплантации из-за более редкой смены повязок, что снижает риск травм кожи и инфекций в месте выхода катетера, более удобны для пациентов и медсестер. Кроме того, хотя гелевые подушечки относительно дороги, их использование более экономично, в связи с меньшими ежедневными расходами (в 1.5-2.5 раза ниже, чем при использовании других типов повязок) и меньшей частотой катетер-ассоциированных инфекций.

\section{Ключевые слова}

Центральный венозный катетер (ЦВК), повязки ЦВК dressings, профилактика инфекций, сестринский контроль, дневные расходы 